\title{
Design of interleaved multilayer rosen type piezoelectric transformer for high voltage
} dc/dc applications

Rødgaard, Martin Schøler; Andersen, Thomas; Meyer, Kaspar Sinding; Andersen, Michael A. E.

Published in:

IET Conference Publications

Link to article, DOI:

10.1049/cp.2012.0206

Publication date:

2012

Document Version

Peer reviewed version

Link back to DTU Orbit

Citation (APA):

Rødgaard, M. S., Andersen, T., Meyer, K. S., \& Andersen, M. A. E. (2012). Design of interleaved multilayer rosen type piezoelectric transformer for high voltage dc/dc applications. In IET Conference Publications Institution of Engineering and Technology. https://doi.org/10.1049/cp.2012.0206

\section{General rights}

Copyright and moral rights for the publications made accessible in the public portal are retained by the authors and/or other copyright owners and it is a condition of accessing publications that users recognise and abide by the legal requirements associated with these rights.

- Users may download and print one copy of any publication from the public portal for the purpose of private study or research.

- You may not further distribute the material or use it for any profit-making activity or commercial gain

- You may freely distribute the URL identifying the publication in the public portal 


\title{
DESIGN OF INTERLEAVED MULTILAYER ROSEN TYPE PIEZOELECTRIC TRANSFORMER FOR HIGH VOLTAGE DC/DC APPLICATIONS
}

\author{
M. S. Rødgaard*, T. Andersen*, K. S. Meyer ${ }^{\dagger}$, M. A. E. Andersen* \\ *Technical University of Denmark, DTU Elektro, Ørsteds Plads, building 349, DK-2800 Kgs. Lyngby, Denmark, \\ msr@elektro.dtu.dk \\ †Noliac A/S, Hejreskovvej 18, 3490 Kvistgaard, Denmark
}

Keywords: Piezoelectric transformer, step-up, converter, soft switching

\begin{abstract}
Research and development within piezoelectric transformer (PT) based converters are rapidly increasing as the technology is maturing and starts to prove its capabilities. Especially for high voltage and high step-up applications, PT based converters have demonstrated good performance and DC/AC converters are widely used commercially. The availability of PT based converters for DC/DC applications are very limited and are not that developed yet. I this paper an interleaved multi layer Rosen-type PT for high step-up and high output voltage is developed, for driving a $2.5 \mathrm{kV}$ dielectric electro active polymer actuator [17]. The targeted application utilises an inductor-less half-bridge driving topology, where the reward of eliminating the series inductor is a reduction in component count, size and price. The absence of a series inductance calls for other means to avoid large hard switching losses and obtain soft switching capabilities. This can be achieved by utilising an advantageous PT structure, which is the main advantage of the interleaved Rosen-type PT. Furthermore the design should be further optimised, in order to achieve soft switching capability. The goal of this paper is to develop a soft switching optimised PT, capable of generating output voltages higher than $2 \mathrm{kV}$ from a $24 \mathrm{~V}$ supply voltage. Furthermore finite element method (FEM) has been the main tool through the PT development.
\end{abstract}

\section{Introduction}

The piezoelectric transformer (PT) was originally developed by Rosen in 1957 [16] and utilises piezoelectric ceramics to convert electrical energy through mechanical vibrations. PT based converters have demonstrated good performance and DC/AC converters are widely used commercially, especially for high step-up and high voltage (HV) applications, like LCD backlighting. But they are still limited to these simple applications (with a constant and high frequency AC load) and the availability of PT based converters for DC/DC applications are very limited and are not that developed yet. However new applications, like electro active polymer (EAP) actuators [5][17], require a high and adjustable DC voltage and calls for DC/DC converters of high step-up and high output voltage.

EAP devices are based on polymer materials and change shape as a result of the electrostatic forces, generated by an applied voltage. The EAP technology has a wide potential in applications such as surgical tools, grippers for material handling and valve actuators for example. The EAP material is essentially just a thin film of polymer with an electrode on each side. It can be modulated as a HV capacitor with a very low leakage current and the force generated by the EAP is related to the applied voltage. The voltage required is dependent among others by the thickness of the EAP film. The EAP technology available today has a film thickness of around $80 \mu \mathrm{m}$ [5][17], it has a maximum working voltage of $2.5 \mathrm{kV}$ and requires a voltage above $2 \mathrm{kV}$ to fully utilise it as an actuator

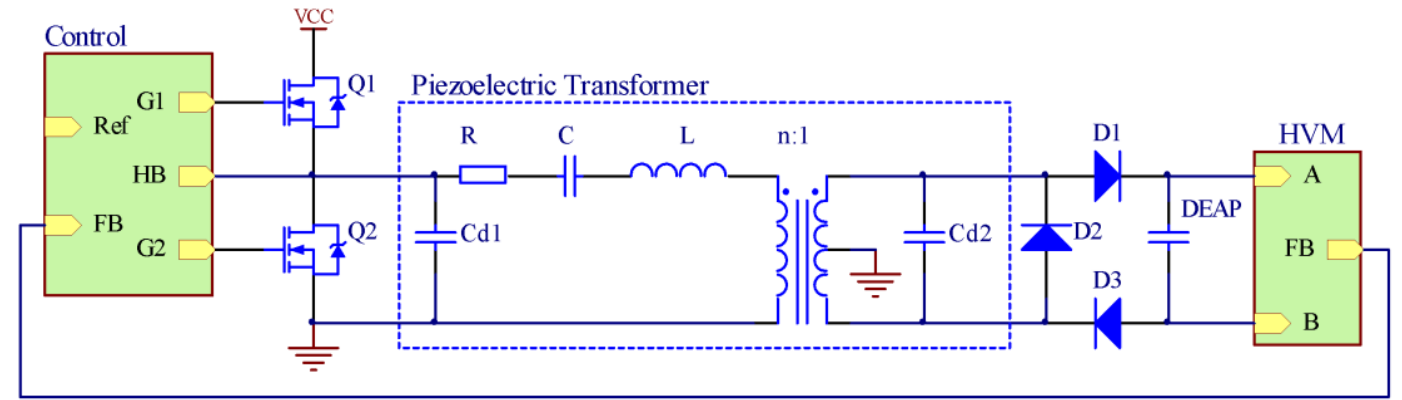

Figure 1: Schematical diagram of the inductor-less half-bridge topology and the PT equivalent lumped parameter model. 
To date, conventional converters utilize electromagnetic components and are the only available HV sources for driven EAP actuators. However these HV converters have poor efficiency, are bulky and provide limited opportunities for miniaturization. PT based converters, on the other hand, are compact and offers high efficiency, especially for high stepup applications. This makes the PT based converter the perfect match for the EAP technology.

In the last decade a lot of research in to the area of PT's has improved Rosen's fist PT and new types of PT's have been developed [4][8][11][14][18]. I this paper an interleaved multi layer Rosen-type PT for high step-up and high output voltage is developed, for driving a $2.5 \mathrm{kV}$ EAP actuator [17]. The specific EAP actuator application is described in more detail in [1] and is similar to the one in [3]. Figure 1 illustrates a schematical diagram of the converter, which utilises an inductor-less half-bridge topology [2][13]. An inductor in series with the PT is usually necessary, in order to achieve soft switching and efficient operation. The absence of a series inductance calls for other means to avoid large hard switching losses and obtain soft switching capabilities. By utilising an advantageous PT structure, soft switching capability can be obtained, which is the main advantage of the interleaved Rosen-type PT. Furthermore the design should be optimised further, in order to obtain soft switching capability. This optimisation has been performed through iterative FEM simulations, as well as the optimisation of the gain and the PT properties in general. Due to the increasing complexity of PT structures and the complexity of the electromechanical behaviour in general, a pure mathematical solution of PT design problems is very challenging, as well as a high degree of knowledge of the electromechanical domain is needed. With today's multi physics FEM simulators, one can finetune PT structures, without having to rewrite the math every time.

As a result an interleaved Rosen-type PT, with a soft switching factor [13] of 1.43 and a gain of 68 has been developed.

\section{Piezoelectric transformer}

PT's are based on a piezoelectric material. This material has an electromechanical coupling and through this coupling a charge displacement is generated, which is proportional to the deformation of the material. A PT is basically two piezoelectric elements which is joined together to form a transformer. The primary side element is then exited by an electrical AC voltage, which induces a deformation of the two joined elements. This deformation generates an output voltage on the secondary side element and with a proper design of the PT, a desired voltage conversion can be obtained from the primary to the secondary side.

In order to convert power at a high efficiency, the PT is operated in one of its resonance modes [8][9][10][11]. The PT resonates each time it is possible to generate a standing wave in the element. But the design is usually optimised for one specific resonance mode, in order to obtain the highest efficiency [9][11].
The PT resembles a distributed network, but for simplicity and mathematical representation, only the resonance mode of interest is modelled [9][10][11]. One of the most used PT models is the lumped parameter model, which was derived by Mason in 1942 [12] and is illustrated in Figure 2.

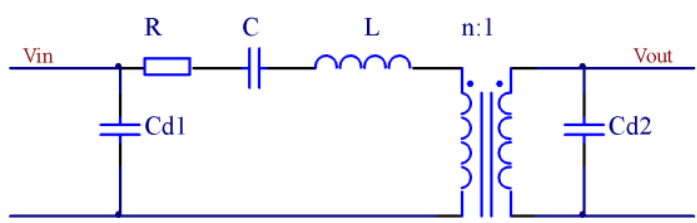

Figure 2: Lumped parameter model, which describes the behaviour of the PT in a narrow band around the opperating resonance mode.

The model is basically a LCC resonance tank and the behaviour of a PT based converter is also quite similar to a traditional resonance converter [6].

\subsection{Piezoelectric transformer design}

The PT developed for this application is essential an interleaved multi layer Rosen-type, meaning that the primary section of the PT has been interleaved into the secondary section. Figure 3 illustrates the structure of the PT, which consists of a primary section with 12 layers, of $166 \mu \mathrm{m}$ in thickness and one split secondary layer. For simplicity the figure only shows two primary layers and the arrows indicate the polarization direction. The PT is build using tape casting technology and the NCE46 piezoelectric material [15]. The PT has the dimensions of $25 \mathrm{~mm} \times 10 \mathrm{~mm} \times 2 \mathrm{~mm}$, but PT's of $20 \mathrm{~mm}, 30 \mathrm{~mm}$ and $35 \mathrm{~mm}$ in length were also designed and produced in the same process.

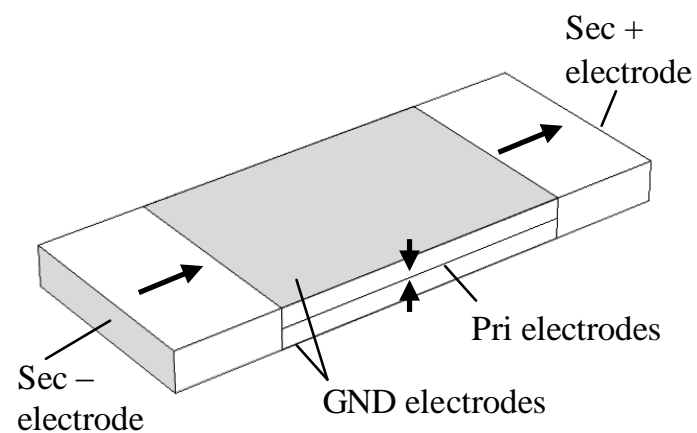

Figure 3: The interleaved multi layer Rosen-type PT structure, where the arrows indicate the polarization direction.

The PT design is quite similar to the one presented in [18], but differs with the polarization of the secondary being in the same direction, as well as it has been optimised for soft switching. Meaning that it is capable of operating the halfbridge under zero voltage switching (ZVS), without any added inductance in series with the PT. The operational vibration resonance is along the longitudinal direction and is generated through the electromechanical coupling factors $\mathrm{k}_{31}$ and $k_{33}$, primary and secondary respectively. In Figure 4 a 
FEM simulation of the operational vibration resonance is shown. The PT operates in its first longitudinal mode shape and it can be seen it has a nodal line in the center of the structure.

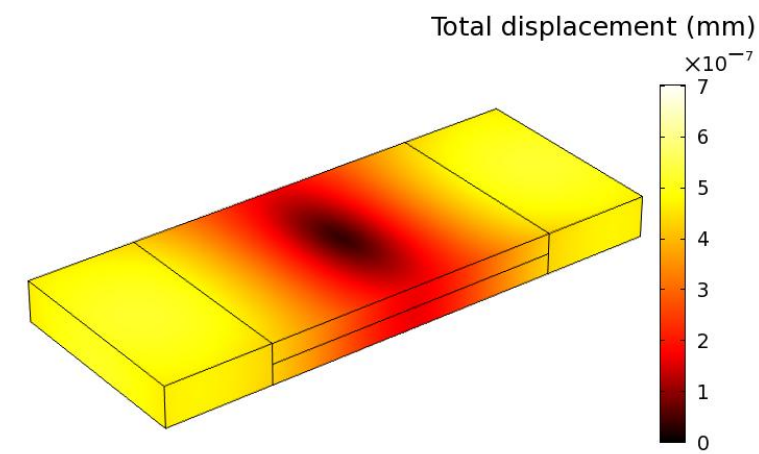

Figure 4: FEM simulation of the PT, operating in the first longitudinal mode shape, at $65.1 \mathrm{kHz}$. The colouring illustrates the total displacement, where dark colours refer to a low displacement and light colours to at high displacement, as the colour bar indicates.

One of the drawbacks of this design, for this application, is the split secondary. This results in a differential output voltage symmetrical around ground, which complicates the electronics somewhat. One could polarise the two half secondary layers in opposite directions, which results in a two layer secondary structure, obtaining a common voltage potential with reference to ground, as in [18]. But this approach would also divide the gain by two, because of two secondary layers, of half the thickness, instead of one full thickness secondary. For this application we need a very high gain, so the extra effort in the electronic is rewarded with a doubling in gain.

\subsection{Piezoelectric transformer development}

The major part of the development has been performed through iterative FEM simulations, where the two main design criteria have been a high gain and the capability of inductor-less operation. In order to utilise an inductor-less topology, the PT should poses soft switching capabilities. This is achieved through the relative location and size of the primary section. Furthermore the PT is operated slightly above the resonance frequency, where the series resonance network becomes inductive and contains enough resonating energy, to charge and discharge the input capacitance $\mathrm{C}_{\mathrm{d} 1}$. The interleaving of the primary section is the main advantage of this design, as this increases the soft switching capability. This is due to the placement right in the middle of the stress curve, which is a half-wave sine wave for the first resonance mode. Furthermore the primary section size has been optimised in order obtain soft switching capability.

Rosen-type PT's has a native high gain, which is good for this application. The gain is mainly determined by the thickness of the primary layers, but of course the primary section size also affects the gain.
Figure 5 shows a frequency sweep of the primary and secondary impedance, around the operating resonance mode. In order to evaluate the electrical characteristics of the PT, the lumped parameter model should be created.

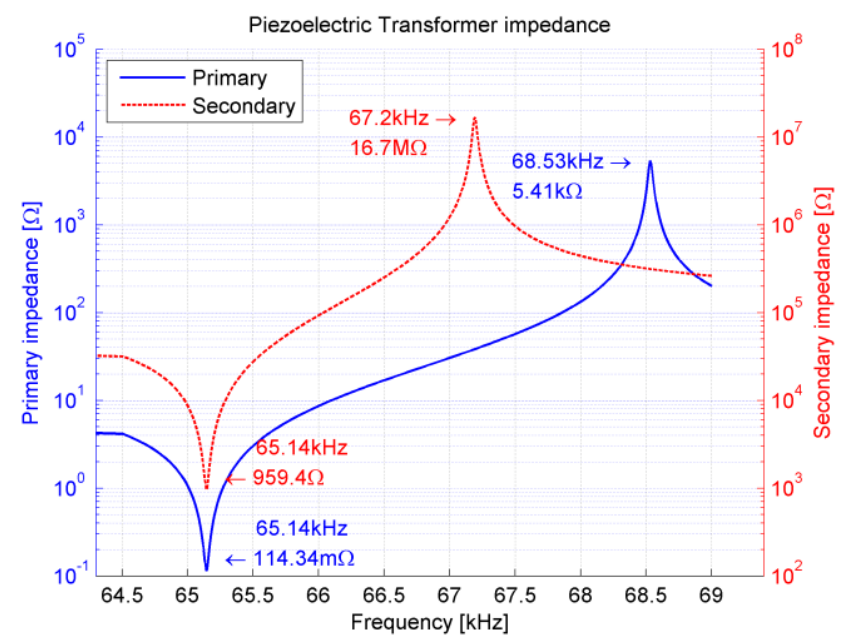

Figure 5: FEM simulation of the PT primary and secondary impedance magnitude, with the opposite side shorted.

The lumped parameters are calculated from the primary and secondary impedance resonance and anti-resonance, plus a DC impedance measurement, as described in detail in [13]. Trough the FEM simulation of the PT impedance Figure 5, the equivalent parameters of Table 1 are found.

\begin{tabular}{|l|l|l|l|l|l|}
\hline $\mathrm{R}$ & $\mathrm{C}$ & $\mathrm{L}$ & $\mathrm{C}_{\mathrm{d} 1}$ & $\mathrm{C}_{\mathrm{d} 2}$ & $1 / \mathrm{n}$ \\
\hline $114 \mathrm{~m} \Omega$ & $9.8 \mathrm{nF}$ & $609 \mu \mathrm{H}$ & $91.7 \mathrm{nF}$ & $17.5 \mathrm{pF}$ & 93.5 \\
\hline
\end{tabular}

Table 1: PT equivalent lumped parameters obtained through FEM simulations.

From the lumped parameters some more general performance properties of the PT can be calculated, as the soft switching factor, matched load, power in matched load, gain and efficiency.

The load is usually matched to the output capacitance $\mathrm{C}_{\mathrm{d} 2}$ of the PT, Equation (1), or the other way around, because this maximises the power transfer of the resonance network to the load. Furthermore all the following performance properties assume a matched load.

$$
R_{\text {match }}=\frac{1}{C_{d 2} \omega_{r}}
$$

Equation (2) expresses the soft switching factor or ZVS factor, which is derived in [13] and is a measure of the PT's soft switching capabilities. If the ZVS factor is more than 1, the PT is capable of performing ZVS at the half-bridge, operated with a matched load.

$$
V_{P}^{\prime}=\frac{1}{n^{2}} \frac{C_{d 2}}{C_{d 1}} \frac{32 \sqrt{6}}{9 \pi^{2}} \eta
$$


Through our own experience, this equation has its short comings, properly because of some of the assumption in the derivation, which is demonstrated in detail in [7]. But it has shown to predict soft switching when working with factors above approximately 1.4 and it is very simple and straight forward to use, compared to the one derived in [7].

Equation (2) is the maximal obtainable soft switching capability, which is located slightly above the resonance frequency, where the series resonance network becomes inductive and contains enough resonating energy, to charge and discharge $\mathrm{C}_{\mathrm{d} 1}$, if the soft switching factor is above 1.4.

The efficiency Equation (3) is a small signal efficiency, because the FEM simulation is only a small signal simulation of the impedance. Furthermore the loss mechanisms of piezoelectric materials are not fully implemented in the FEM simulation, therefore the efficiency is mostly just a measure to compare between different designs.

$$
\eta_{\text {match }}=1-\frac{2 R C_{d 2}}{n^{2} \sqrt{L C}}
$$

The following PT properties of Table 2 are found from the equivalent parameters of Table 1 and the index "ZVS" is referring to that the $\mathrm{PT}$ is operating at its maximum ZVS point.

\begin{tabular}{|l|l|l|l|l|l|}
\hline $\mathrm{V}_{\mathrm{P}}$ & $\mathrm{A}_{\mathrm{ZVS}}$ & $\mathrm{P}_{\mathrm{ZVS}}$ & $\mathrm{R}_{\text {match }}$ & $\eta$ & $\mathrm{V}_{\text {out,rms }}$ \\
\hline 1.45 & 75.3 & $3.79 \mathrm{~W}$ & $138 \mathrm{k} \Omega$ & 0.986 & $728 \mathrm{~V}$ \\
\hline
\end{tabular}

Table 2: PT equivalent lumped parameter model performance properties.

Evaluating these properties it can be seen that it has a sufficient high ZVS factor of 1.45 , which enables the inductor-less operation, a high efficiency and a high gain. The high gain results in a $728 \mathrm{~V}_{\text {rms }}$ output voltage, into a matched load, with a PT modulation voltage of $9.67 \mathrm{~V}_{\text {rms. }}$. The PT modulation voltage is the first harmonic, of the $24 \mathrm{~V}$ input voltage, as derived in [13].

\section{Experimental results}

In the following section the functionality and properties of the received prototype PT's are verified.

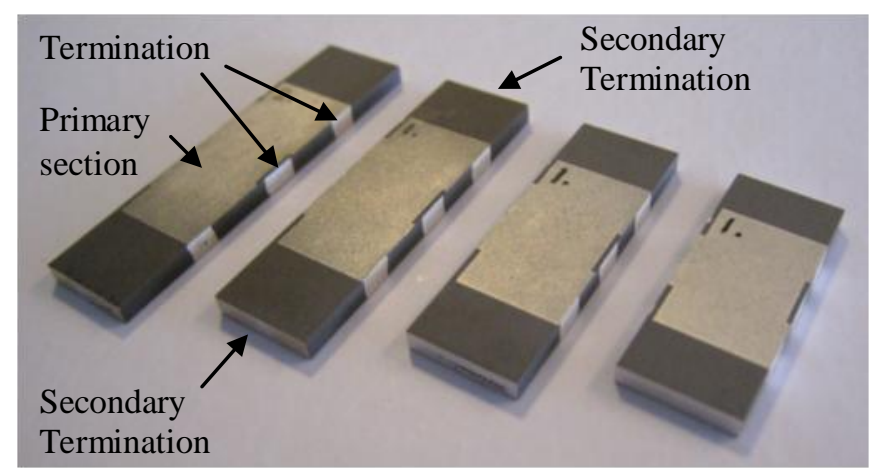

Figure 6: Picture of prototype PT's of different sizes (length from left: $35 \mathrm{~mm}, 30 \mathrm{~mm}, 25 \mathrm{~mm}$ and $20 \mathrm{~mm}$ ).
Figure 7 shows an impedance measurement of one of the prototype PT's and from these measurements the equivalent lumped parameters of Table 3 and the performance properties of Table 4 are calculated.

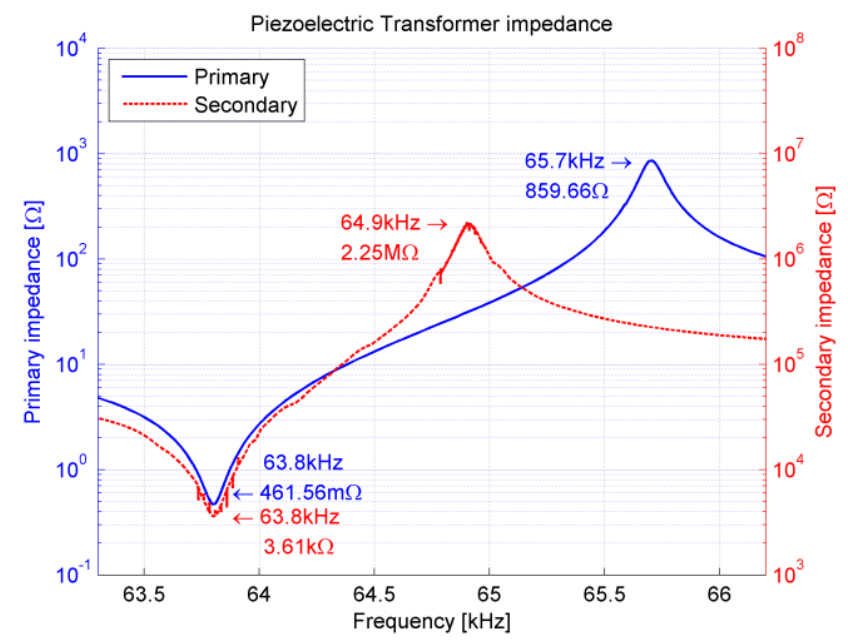

Figure 7: Measurement of prototype PT primary and secondary impedance magnitude, performed with a HP4194A impedance/gain-phase analyzer.

\begin{tabular}{|l|l|l|l|l|l|}
\hline $\mathrm{R}$ & $\mathrm{C}$ & $\mathrm{L}$ & $\mathrm{C}_{\mathrm{d} 1}$ & $\mathrm{C}_{\mathrm{d} 2}$ & $1 / \mathrm{n}$ \\
\hline $462 \mathrm{~m} \Omega$ & $6.74 \mathrm{nF}$ & $923 \mu \mathrm{H}$ & $112 \mathrm{nF}$ & $24.8 \mathrm{pF}$ & 88.6 \\
\hline
\end{tabular}

Table 3: Prototype PT equivalent lumped parameters obtained through impedance measurements.

\begin{tabular}{|l|l|l|l|l|l|}
\hline $\mathrm{V}_{\mathrm{P}}{ }_{\mathrm{P}}$ & $\mathrm{A}_{\mathrm{ZVS}}$ & $\mathrm{P}_{\mathrm{ZVS}}$ & $\mathrm{R}_{\text {match }}$ & $\eta$ & $\mathrm{V}_{\text {out,rms }}$ \\
\hline 1.43 & 67.5 & $4.23 \mathrm{~W}$ & $100 \mathrm{k} \Omega$ & 0.933 & $653 \mathrm{~V}$ \\
\hline
\end{tabular}

Table 4: Prototype PT equivalent lumped parameter model performance properties.

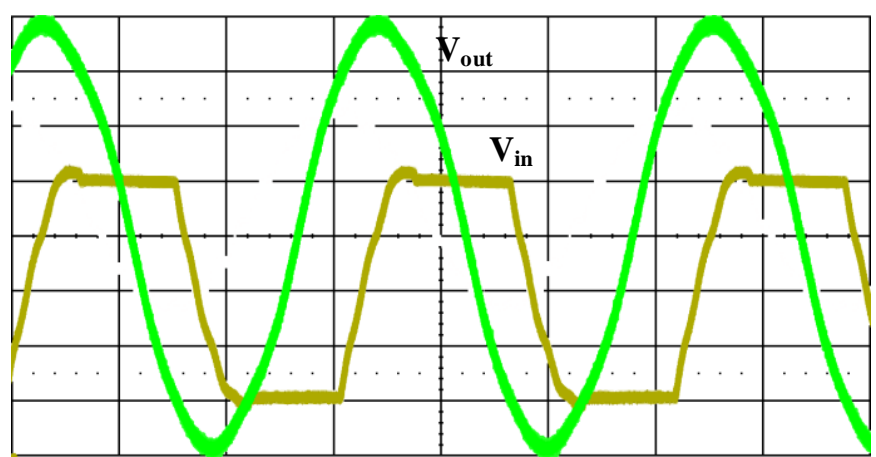

Figure 8: Measurement of the output voltage in to a matched load (green) and input half-bridge voltage (yellow), which clearly is operating under ZVS. Time base [ $5 \mu \mathrm{s} / \mathrm{div}$ ], output voltage [200V/div] and input half-bridge voltage [5V/div].

Figure 8 shows the PT operating with a half-bridge voltage of $20 \mathrm{~V}$ and with a matched resistive load. From the input voltage waveform, it can clearly be seen that the half-bridge is operating under ZVS, which verifies the designs soft switching capability. Looking at the output voltage it resembles a nice sine wave, with a peak voltage of 
approximately $780 \mathrm{~V}$, from which the gain of Equation (4) can be calculated.

$$
A_{\text {ZVS }}=\frac{\left|V_{\text {out }}\right|}{\left|V_{\text {in }}\right|}=\frac{780 \mathrm{~V}}{0.57 \cdot 20 \mathrm{~V}}=68.2
$$

Where 0.57 is the approximate amplitude of the first harmonic of a trapezoidal waveform, as derived in [13]. When employing a rectifying voltage doubler instead of a matched load, voltages over $2 \mathrm{kV}$ can be achieved for DC/DC applications.

\section{Discussion}

Comparing measured figures (Table 3 and Table 4) with the FEM simulation obtained figures (Table 1 and Table 2), it can be seen that the gain $\left(\mathrm{A}_{\mathrm{zvs}}\right)$ is $10 \%$ lower than expected. This is partly because the prototype build-up were $2.1 \mathrm{~mm}$ high, which is $0.1 \mathrm{~mm}$ higher than expected, making the primary layers 5\% higher and this results in a 5\% decrease in gain. Furthermore there is some inactive piezoelectric material in the primary section, due to the termination of the primary electrodes on the side of the PT, as shown in Figure 6. For simplicity the termination is not included in the FEM simulation, which accounts for some of the remaining $5 \%$ deviation. Hence there is a very good correlation between the FEM model and the prototype concerning the gain. Comparing the gain of Equation (4) with the calculated from the lumped parameters (Table 4), it can be seen that there is a very good correlation between a fully stressed PT and the small signal impedance measurement.

The correlation between the soft switching factors $\left(\mathrm{V}_{\mathrm{P}}{ }_{\mathrm{P}}\right)$ is also very good.

Looking at the capacitances $\mathrm{C}_{\mathrm{d} 1}, \mathrm{C}_{\mathrm{d} 2}$ and the efficiency, the correlation is not that good. This is expected to be because of a bad correlation between the NCE46 material parameters in the FEM model and what they are in real life, as well as an incomplete loss model in the FEM simulation. Nevertheless the FEM simulation makes it possible to design soft switching optimised PT's for inductor-less operation, having a desired soft switching factor, a desired gain, as well as the possibility to compare the performance between different designs. For this specific case there is not a well defined resistive load and the load matching inaccuracy is therefore not a problem.

\section{Conclusion}

In this paper a new interleaved multi layer Rosen-type piezoelectric transformer (PT), optimised for soft switching, inductor-less operation and high output voltage has been developed. The development has been performed through iterative finite element method simulations, which has proven its capabilities as a good design tool for PT development. The measurements of the prototype PT showed a good correlation between the design and the prototype. The prototype PT has demonstrated to have a sufficiently high soft switching factor of 1.43 to operate in an inductor-less topology, as well as having a high gain of 68 , enabling the generation of high output voltages.

\section{Acknowledgements}

Finally we would like to thanks Noliac A/S for the production of prototype PT's, as well as general PT design support. We would also like to thanks Danfoss PolyPower A/S for supplying the application and EAP actuators.

\section{References}

[1] T. Andersen, M. S. Rødgaard, O. C. Thomsen, M. A. E. Andersen, "Low voltage driven dielectric electro active polymer actuator with integrated piezoelectric transformer based driver", SPIE Electroactive Polymer Actuators and Devices (EAPAD), Volume 7976, pp. $79762 \mathrm{~N},(2011)$

[2] J. M. Alonso, C. Ordiz, M. A. D. Costa, J. Ribas, J. Cardesín, " High-Voltage Power Supply for Ozone Generation Based on Piezoelectric Transformer", IEEE TRANSACTIONS ON INDUSTRY APPLICATIONS, VOL. 45 NO. 4, 1513-1523 (2009)

[3] C. Bai, S. Li, Shen Q., D. Cui, "A Converter of High Voltage Capacitor Charging Power Supply Using Piezoelectric Transformer", APPEEC, 2009

[4] E. M. Baker,"Design of Radial Mode Piezoelectric Transformers for Lamp Ballast Applications", PhD thesis, Blacksburg Virginia (2002)

[5] M. Y. Benslimane, HE. Kiil, M. J. Tryson, "Dielectric electro-active polymer push actuators: performance and challenges", Society of Chemical Industry, Wiley Interscience, 415-421 (2010)

[6] W. R. Erikson, D. Maksimovié, [Fundamentals of Power Electronics], Springer Science+Business Media inc., (2001)

[7] E. L. Horsley, N. Nguyen-Quang, M.P. Foster, D. A. Stone, "Achieving ZVS in inductor-less half-bridge piezoelectric transformer based resonant converters", PEDS, 2009, 446-451

[8] E. L. Horsley, M. P. Foster, D. A. Stone, "State-of-theart Piezoelectric Transformer Technology", European Conference on Power Electronics and Applications, 1$10(2007)$

[9] C. Y. Lin, "Design and analysis of piezoelectric transformer converters," PhD dissertation, Blacksburg Virginia, (1997)

[10] F. L. CY. Lin, "Design of a piezoelectric transformer converter and its matching networks", Power Electronics Specialists Conference, PESC' 94 Record, (1994)

[11] R. L. Lin, "Piezoelectric Transformer Characterization and Application of Electronic Ballast", $P h D$ dissertation, Blacksburg Virginia (2001)

[12] W. P. Mason, "Electromechanical Transducers and Wave Filters", D. Van Nostrand Co, (1942)

[13] K. S. Meyer, M. A. E. Andersen," Parameterized Analysis of Zero Voltage Switching in Resonant Converters for Optimal Electrode Layout of 
Piezoelectric Transformers", PESC IEEE, 978-1-42441668-4, 2543-2548 (2008)

[14] J. C. J. Navas, T. Bove, K. Breboel, "Miniaturised battery charger using piezoelectric transformers", Applied Power Electronics Conference and Exposition, APEC 2001 Sixteenth Annual IEEE, vol.1, 492-496 (2001)

[15] Noliac A/S Piezoelectric ceramics datasheet, http://www.noliac.com/Files/Billeder/02\%20Standard/C eramics/Noliac_CEramics_NCE_datasheet.pdf

[16] C. A. Rosen, "Ceramic transformers and filters", Proc. Electron. Comp. Symp. 205-211, (1957).

[17] M. Tryson, HE. Kiil, M. Benslimane, "Powerful tubular core free dielectric electro activate polymer (DEAP) 'PUSH' actuator", SPIE, Vol. 7287, (2009)

[18] CHU Xiang-cheng, WU Jun-fei, XU Zhi-han, LI Longtu, "EXPERIMENT RESEARCH ON MULTILAYER PIEZOELECTRIC TRANSFORMER", IEEE 978-14244-2891-5, 524-527 (2008) 